\title{
Single port transoral thyroidectomy
}

\author{
Daqi Zhang ${ }^{1}$, Hoon Yub Kim², Ralph P. Tufano ${ }^{3}$, Gianlorenzo Dionigi ${ }^{4}$ \\ ${ }^{1}$ Division of Thyroid Surgery, China-Japan Union Hospital of Jilin University, Jilin Provincial Key Laboratory of Surgical Translational Medicine, \\ Jilin Provincial Precision Medicine Laboratory of Molecular Biology and Translational Medicine on Differentiated Thyroid Carcinoma, Changchun \\ 130033, China; ${ }^{2}$ Department of Surgery, KUMC Thyroid Center, Korea University Hospital, Korea University College of Medicine, Seoul, Korea; \\ ${ }^{3}$ Department of Otolaryngology-Head and Neck Surgery, The Johns Hopkins University School of Medicine, Baltimore, MD, USA; ${ }^{4}$ Division for \\ Endocrine and Minimally Invasive Surgery, Department of Human Pathology in Adulthood and Childhood "G. Barresi”, University Hospital G. \\ Martino, University of Messina, Messina, Italy \\ Correspondence to: Gianlorenzo Dionigi. Division for Endocrine and Minimally Invasive Surgery, Department of Human Pathology in Adulthood and \\ Childhood “G. Barresi”, University Hospital G. Martino, University of Messina, Messina, Italy. Email: gdionigi@unime.it. \\ Provenance and Peer Review: This article was commissioned by the Editorial Office, Gland Surgery. This article did not undergo external peer review. \\ Comment on: Chan JYK, Koh YW, Richmon J, et al. Transoral thyroidectomy with a next generation flexible robotic system: a feasibility study in a \\ cadaveric model. Gland Surg 2019;8:644-7.
}

Submitted Dec 29, 2019. Accepted for publication Jan 16, 2020.

doi: $10.21037 /$ gs.2020.01.09

View this article at: http://dx.doi.org/10.21037/gs.2020.01.09

\section{Introduction}

Today endoscopic thyroidectomy (ET) has changed thyroid surgery (1).

Let's take for example the ET first propose and applied by Miccoli, i.e., the minimally invasive video-assisted thyroidectomy (MIVAT) $(1,2)$. ET is gold standard when opting for an indeterminate small thyroid nodule, ET is preferred for the cosmetic outcomes and MIVAT is comparable to open surgery for T1 thyroid tumors (1-4).

Transoral thyroidectomy (TT) is rapidly evolving, gained popularity as a thyroidal alternative for endocrine endoscopic procedures $(5-10)$. There is a groin feeling that TT may replace other endoscopic procedures both remote and neck access (11-18). Although TT is an expanding new surgery, studies are confined by few Institutions (19-24).

A study group for TT has been established in 2016 to optimize standards (21).

We read with interest the paper by Chan "Transoral thyroidectomy with a next generation flexible robotic system: a feasibility study in a cadaveric model" published on Gland Surgery (25).

Robotic thyroidectomy may be the evolutionary formula of ET (Figure 1). The robotic system allows the endocrine surgeon to continuously articulate all the movements of the human hand and wrist within the neck patient and provides the surgeon with a stereoscopic vision obtained thanks to the use of a video-two-channel optical endoscope and dual 3CCD high resolution camera (11-14). This realtime magnification system allows the surgeon to have a remarkable image quality compared to traditional surgery (11-14). The system provides more than a thousand images per second and the processor filters every single image eliminating background noise (11-14). It also allows scaling of the instruments and the filtering of the trembling of the surgeon's hands. The movement activation module allows an accurate and fluid movement of the instrumentation on the operating theater (11-14).

Preliminary scientific papers testify to the advantages of robotic TT compared to traditional surgery and endoscopic TT (11-14). An important advantage is a better removal of central compartment lymph nodes (for oncological procedures) (11-14).

The introduction of robotic platform in combination with single port technology is promising and may overcome limits of standard endoscopic TT (25).

The single port TT is a project that was born in the wake of needs that may appear minimal, but which is prodigal of large developments (Table 1). This single access is used as an alternative to the 3-4 usual accesses necessary for transoral surgical intervention with the robot or the endoscope, for interventions on both benign and malignant thyroid disease. The introduction of the optics, the operating and 


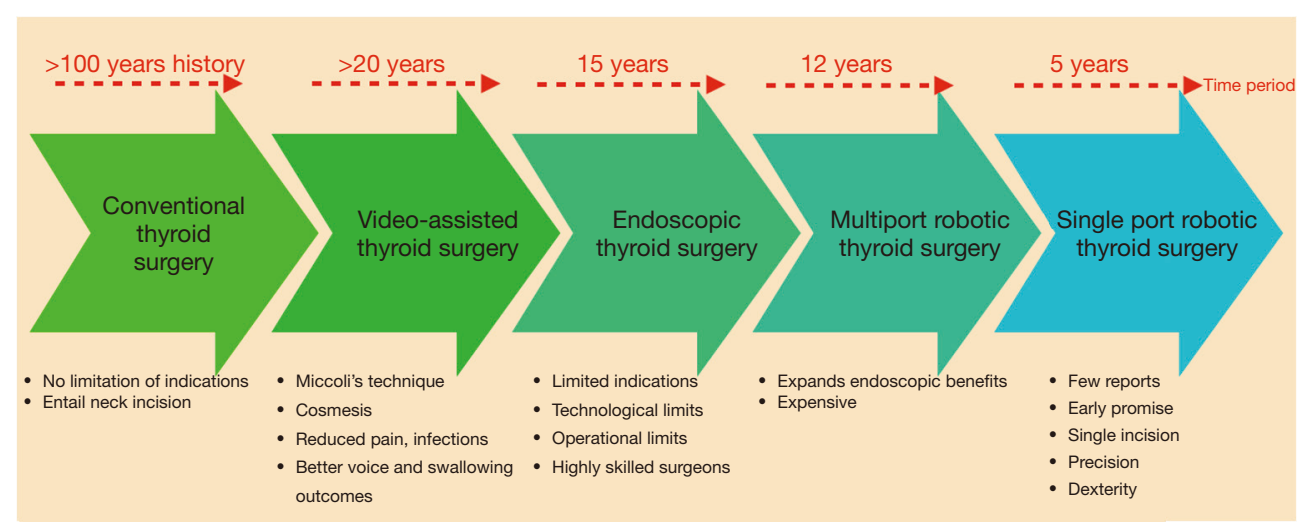

Figure 1 The consistency of conventional thyroid surgery, and evolution of neck endocrine procedures from conventional open thyroidectomy to the present state of techniques, equipments and approaches. Are we going to the right direction?

Table 1 Current status of robotic single-port surgery indications

Robotic single port procedures
Radical prostatectomy
Rectal surgery
Hysterectomy
Transanal surgery
Cholecystectomy
Sacrocolpopexy
Hernia surgery
Thymectomy
Transoral head and neck surgery
Adrenalectomy
Nephrectomy
Distal pancreatectomy
Subtotal gastrectomy

Table 2 Merits of transoral robotic thyroidectomy

Advantages of transoral robotic thyroidectomy
Optimal cosmetic results
The concept of NOTES
Real minimally invasive surgery
Easy access to subplatysmal space
Possible radical central neck dissection

assisted instruments, through a single access of only $2 \mathrm{~cm}$ in diameter at the navel level, entails the crossing of the instruments themselves inside the abdominal cavity to allow the operator to have sufficient maneuvering space: to understand each other, the right hand operates the tool that comes from the left in the operating field and the left hand the tool that comes from the right, like working in the mirror $(11-14,25)$. The robot with a special program "automatically straightens" the commands of the robotic arms, so the surgeon can use operating instruments with total naturalness without the need for any dexterity effort.

The workforce of this experimental study by Chan et al. is to have validated the use of single port TT and dedicated flexible tools for TT (25). Potentially, the idea of applying single port for TT surgery is proper. De facto, unlike abdominal single port surgery, the spaces in the neck are narrow and can better underline and emphasize the potentials of the single port principles, similarly to the advantages of single port transanal endoscopic microsurgery (TEM). Likely, single port TT is going to further improve standard TT (Table 2).

The need is to rigorously evaluate single port TT. There are essential issues that should be answered until single port TT will be equivalent with standard TT.

Is there benefit of single port TT for the candidates in terms of morbidity rates, and oncological concerns? Less postoperative pain, faster recovery and shorter hospital stay when compared to the traditional TT are unproven potential advantages of single port surgery. 

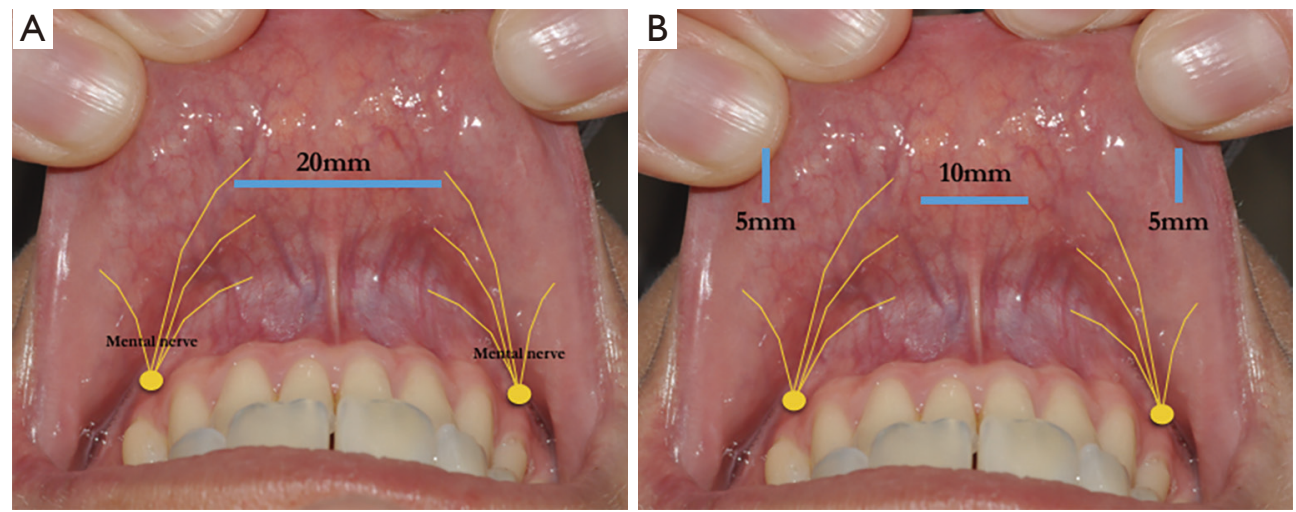

Figure 2 Comparison between single port TT (A) and standard endoscopic TT (B) vestibular incisions. The vestibular incision length for the single port TT is about $2 \mathrm{~cm}$. Can a major central vestibular surgical incision for the single port insertion, the size, geometry, shape and materials of the single port accessory lead to a higher incidence of mental nerve injury? TT, transoral thyroidectomy.

The vestibular incision length for the single port TT is $>1.5 \mathrm{~cm}$ (25). Can a major central vestibular surgical incision for the single port insertion, the size, geometry, shape and materials of the single port accessory lead to a higher incidence of mental nerve injury? Single port TT should be designed to give surgeons the ability to use multiple instruments with maximal maneuverability during thyroidectomy through adjustable cannulas all within a soft, atraumatic one port (Figure 2).

How can we prevent single port displacement during TT?

How much is the single port?

In general, single port surgery determines a challenge and increases surgeons' skills and ambidexterity. Should we limit surgeons comfort and confidence during single port TT? Single port TT should maintain the hidden scar in the vestibule, with no extra incisions. We should constantly weight the basic endocrine clinical and oncological principles of standard thyroidectomy.

The versatility of the single port accessory is important. It is better to have multiple operating channels, for multiple surgical instruments and not to limit only 3 operating channels? For example, an additional $4^{\text {th }}$ operator channel for retraction, suction, better endoscopic vision, nerve monitoring (intermitted and/or continuous) while dissection should be added. In general, the movability of endoscopic accessories is challenging using the single port device.
Furthermore, hindrance of working instruments results in limited operating fields. The introduction of new advanced endoscopic tools (as reticulating forces, flexible scissors, articulating graspers) tend to overcome these limits (25). Conversion of endoscopy and robotics instrumentation surely may determine in better functional and oncological results.

Which candidates will actually benefit and what are the indications for single port TT? Who will mainly benefit from single port TT? Are candidates identical to standard TT? The ideal indications to start with single port TT are: (I) patients who are most concerned of cosmesis, (II) subtotal thyroid resections, (III) benign thyroid lesion (oncological compromise), (IV) lobectomies. (V) Patients with conventional contraindications to ET, should not be the candidates for single port TT (1).

Single port TT is an exiting opportunity to improve technology for both open, endoscopic and robotic thyroidectomy. Potentially, single port in TT surgery may give greater results than the single port technology in abdominal surgery. Whether single port TT is a superior or equally technique compared to standard TT has to be proven by future prospective randomized trials.

\section{Acknowledgments}

Funding: None. 


\section{Footnote}

Conflicts of Interest: RPT serves as the unpaid editorial board member of Gland Surgery from Sep 2018 to Aug 2020. The other authors have no conflicts of interest to declare.

Ethical Statement: The authors are accountable for all aspects of the work in ensuring that questions related to the accuracy or integrity of any part of the work are appropriately investigated and resolved.

Open Access Statement: This is an Open Access article distributed in accordance with the Creative Commons Attribution-NonCommercial-NoDerivs 4.0 International License (CC BY-NC-ND 4.0), which permits the noncommercial replication and distribution of the article with the strict proviso that no changes or edits are made and the original work is properly cited (including links to both the formal publication through the relevant DOI and the license). See: https://creativecommons.org/licenses/by-nc-nd/4.0/.

\section{References}

1. Dionigi G, Dralle H, Materazzi G, et al. Happy 20th birthday to minimally invasive video-assisted thyroidectomy! J Endocrinol Invest 2020;43:385-8.

2. Dionigi G, Boni L, Duran-Poveda M. Evolution of endoscopic thyroidectomy. Surg Endosc 2011;25:3951-2; author reply 3953.

3. Dionigi G. Evidence-based review series on endoscopic thyroidectomy: real progress and future trends. World J Surg 2009;33:365-6.

4. Miccoli P, Dionigi G. Tailored approach for recurrent laryngeal nerve dissection according to different endoscopic endocrine surgery. Head Neck 2019;41:4060-1.

5. Zhang D, Fu Y, Dionigi G, et al. Human cadaveric model for studying the preservation of mental nerve during transoral endoscopic thyroidectomy. Surg Radiol Anat 2020;42:55-62.

6. Zhang D, Li S, Dionigi G, et al. Animal study to evaluate the effect of carbon dioxide insufflation on recurrent laryngeal nerve function in transoral endoscopic thyroidectomy. Sci Rep 2019;9:9365.

7. Zhang D, Li S, Dionigi G, et al. Stimulating and dissecting instrument for transoral endoscopic thyroidectomy: proof of concept investigation. Surg Endosc 2020;34:996-1005.

8. Zhang D, Park D, Sun H, et al. Indications, benefits and risks of transoral thyroidectomy. Best Pract Res Clin Endocrinol Metab 2019;33:101280.

9. Zhang D, Caruso E, Sun H, et al. Classifying pain in transoral endoscopic thyroidectomy. J Endocrinol Invest 2019;42:1345-51.

10. Celik S, Makay O, Yoruk MD, et al. A surgical and anatomo-histological study on transoral endoscopic thyroidectomy vestibular approach (TOETVA). Surg Endosc 2020;34:1088-102.

11. You JY, Kim HY, Chai YJ, et al. Transoral robotic thyroidectomy versus conventional open thyroidectomy: comparative analysis of surgical outcomes in thyroid malignancies. J Laparoendosc Adv Surg Tech A 2019;29:796-800.

12. Sun H, Dionigi G. Applicability of transoral robotic thyroidectomy: Is it the final solution? J Surg Oncol 2019;119:541-2.

13. Kim HK, Chai YJ, Dionigi G, et al. Transoral robotic thyroidectomy for papillary thyroid carcinoma: perioperative outcomes of 100 consecutive patients. World J Surg 2019;43:1038-46.

14. Kim HK, Kim HY, Chai YJ, et al. Transoral robotic thyroidectomy: comparison of surgical outcomes between the da Vinci Xi and Si. Surg Laparosc Endosc Percutan Tech 2018;28:404-9.

15. Zhang D, Wu CW, Inversini D, et al. Lessons learned from a faulty transoral endoscopic thyroidectomy vestibular approach. Surg Laparosc Endosc Percutan Tech 2018;28:e94-9.

16. Russell JO, Anuwong A, Dionigi G, et al. Transoral thyroid and parathyroid surgery vestibular approach: a framework for assessment and safe exploration. Thyroid 2018;28:825-9.

17. Chai YJ, Kim HY, Kim HK, et al. Comparative analysis of 2 robotic thyroidectomy procedures: transoral versus bilateral axillo-breast approach. Head Neck 2018;40:886-92.

18. Dionigi G, Chai YJ, Tufano RP, et al. Transoral endoscopic thyroidectomy via a vestibular approach: why and how? Endocrine 2018;59:275-9.

19. Chai YJ, Chung JK, Anuwong A, et al. Transoral endoscopic thyroidectomy for papillary thyroid microcarcinoma: initial experience of a single surgeon. Ann Surg Treat Res 2017;93:70-5.

20. Kim HY, Chai YJ, Dionigi G, et al. Transoral robotic thyroidectomy: lessons learned from an initial consecutive series of 24 patients. Surg Endosc 2018;32:688-94.

21. Anuwong A, Sasanakietkul T, Jitpratoom P, et al. 
Transoral endoscopic thyroidectomy vestibular approach (TOETVA): indications, techniques and results. Surg Endosc 2018;32:456-65.

22. Dionigi G, Lavazza $M, W u$ CW, et al. Transoral thyroidectomy: why is it needed? Gland Surg 2017;6:272-6.

23. Russell JO, Clark J, Noureldine SI, et al. Transoral thyroidectomy and parathyroidectomy - a North American series of robotic and endoscopic transoral approaches to

Cite this article as: Zhang D, Kim HY, Tufano RP, Dionigi G. Single port transoral thyroidectomy. Gland Surg 2020;9(2):159-163. doi: 10.21037/gs.2020.01.09 the central neck. Oral Oncol 2017;71:75-80.

24. Dionigi G, Tufano RP, Russell J, et al. Transoral thyroidectomy: advantages and limitations. J Endocrinol Invest 2017;40:1259-63.

25. Chan JYK, Koh YW, Richmon J, et al. Transoral thyroidectomy with a next generation flexible robotic system: a feasibility study in a cadaveric model. Gland Surg 2019;8:644-7. 